\title{
PENGARUH PENGGUNAAN AIR VENT TUBE TURBULANCE (AVTT) TERHADAP KINERJA MESIN MOTOR MATIK 4 LANGKAH
}

\author{
Komarudin $^{1}$, Primson Yohanes ${ }^{2}$ \\ Program Studi Teknik Mesin, Institut Sains dan Teknologi Nasional, Jakarta, Indonesia ${ }^{12}$ \\ Email: komarudin.mt@gmail.com
}

\begin{abstract}
Automatic motor engine 4 stroke system uses a carburetor engine is still less than optimal performance. To overcome these problems it created tools that the air intake tube Turbulent Air Vent Tube (AVTT). AVTT is a tool that serves to improve the quality of air intake into the cylinder motor fuel, by changing the air flow laminar to turbulent flow so that the fuel combustion process is ideal close to perfect. AVTT tube designed using aluminum material types AVTT in 6069. Installation of the air filter duct size is adjusted to the motor air filter diameter hole. To determine the performance of a motorcycle engine can be made by automatic test engine performance using a dynamometer. Tests conducted to analyze the effect of the use of AVTT on engine performance includes the automatic motor torque, data, air fuel ratio and fuel consumption. The test results showed that the use AVTT able to increase the torque of $0.06-13.74 \%$, power from $0.08-13.74 \%$, and the air fuel ratio of 18: 1 - 10: 1, and can reduce fuel consumption 2 - $9 \%$ in both engine variants automatic motor 4 stroke.
\end{abstract}

Keywords: Motor matic, dynamometer, torque and power, fuel consumption

\section{LATAR BELAKANG}

Pada saat ini di indonesia harga bahan bakar minyak yang mahal dan keterbatasan persediaannya, para konsumen motor saat ini kebanyakan mulai memakai kendaraan bermotor menggunakan sitem Electrical Fuel Injection (EFI), yang lebih ramah lingkungan dan lebih ekonomis. Oleh karena itu kebanyakan konsumen sepada motor lebih memilih menggunakan motor sistem injeksi dan mulai meninggalkan motor menggunakan sistem karburator. Kendaraan bermotor yang menggunakan sistem karburator kinerja mesinnya masih belum optimal, sebagai salah satu solusi untuk lebih mengoptimalkan kinerja mesin khususnya pada sistem pembakaran maka dibuat alat Air Vent Tune Turbulent (AVTT). AVTT berguna untuk meningkatkan performa mesin, menghemat konsumsi bahan bakar, mengurangi getaran mesin, menambah akselerasi, dan mengurangi emisi gas buang serta lebih efisien dalam perawatan kendaraan.

\section{TINJAUAN PUSTAKA}

Motor bensin empat langkah adalah motor yang setiap satu kali pembakaran bahan bakar memerlukan 4 langkah dan 2 kali putaran poros engkol. prinsip kerja motor 4 langkah dapat dilihat pada Gambar 1.
Langkah lsep

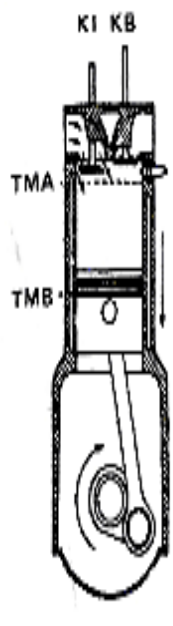

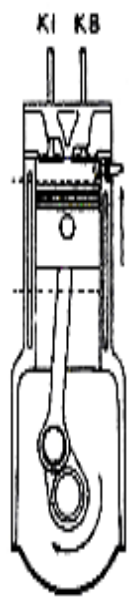

Langkah kompres
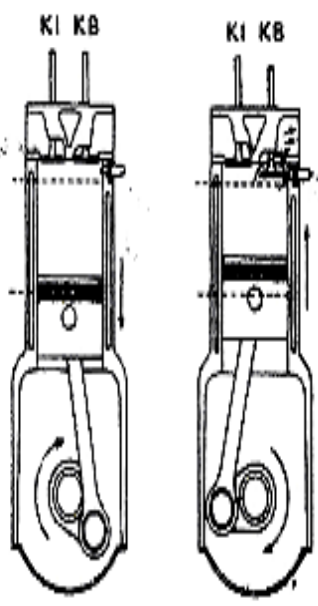

Langkah kerjo

Langkah buang
Gambar 1. Proses kerja mesin 4 langkah

\section{Langkah isap :}

1. Torak bergerak dari TMA ke TMB

2. Katup masuk terbuka, katup buang tertutup

3. Campuran bahan bakar dengan udara yang telah tercampur didalam karburator masuk kedalam silinder melalui katup masuk

4. Saat torak berada di TMB katup masuk akan tertutup

Langkah kompresi :

1. Torak bergerak dari TMB ke TMA

2. Katup masuk dan katup buang kedua-duanya tertutup sehingga gas yang telah diisap tidak keluar pada waktu ditekan oleh torak yang mengakibatkan tekanan gas akan naik. 
3. Beberapa saat sebelum mencapai TMA busi memercikkan bunga api

4. Gas bahan bakar yang telah mencapai tekanan tinggi terbakar.

5. Akibat pembakaran bahan bakar, tekanannya pun akan naik.

\section{Langkah kerja / ekspansi :}

1. Saat ini kedua katup masih dalam keadaan tertutup.

2. Campuran udara dan bahan baka yang telah dikompresi dibakar oleh percikan busi, dengan tekanan yang tinggi akan mengembang kemudian menekan torak turun kebawah dari TMA ke TMB.

3. Tenaga ini disalurkan melalui batang penggerak, dari gerak translasi selanjutnya oleh poros engkol diubah menjadi gerak rotasi.

\section{Langkah pembuangan :}

1. Katup buang terbuka, katup masuk tertutup.

2. Torak bergerak dari TMB ke TMA.

3. Gas sisa pembakaran terdorong oleh torak keluar melalui katup buang.

\section{Siklus Termodinamika}

Konversi energi yang terjadi pada motor bakar torak berdasarkan pada siklus termodinamika. Proses sebenarnya amat komplek untuk dianalisis menurut teori, untuk memudahkan analisis tersebut kita perlu membayangkan suatu keadaan yang ideal. Makin ideal suatu keadaan maka makin mudah dianalisis, akan tetapi dengan sendirinya makin menyimpang dari keadaan yang sebenarnya, sehingga analisa dilakukan pada kondisi ideal dengan fluida kerja udara. Diagram P-V dan T-S siklus ideal termodinamika dapat terlihat pada Gambar 2.
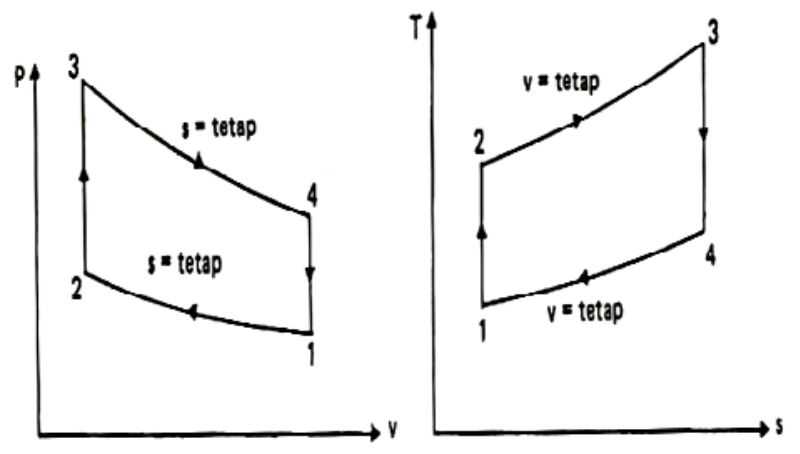

Gambar 2. Diagram P-V dan T-S siklus otto Siklus Otto (Siklus udara volume konstan)

Pada siklus otto atau siklus volume konstan proses pembakaran terjadi pada volume konstan. Adapun langkah dalam siklus otto yaitu gerakan piston dari titik puncak (TMA = titik mati atas) ke posisi bawah $(\mathrm{TMB}=$ titik mati bawah) dalam silinder. Diagram P-V siklus otto dapat dilihat pada Gambar 3.
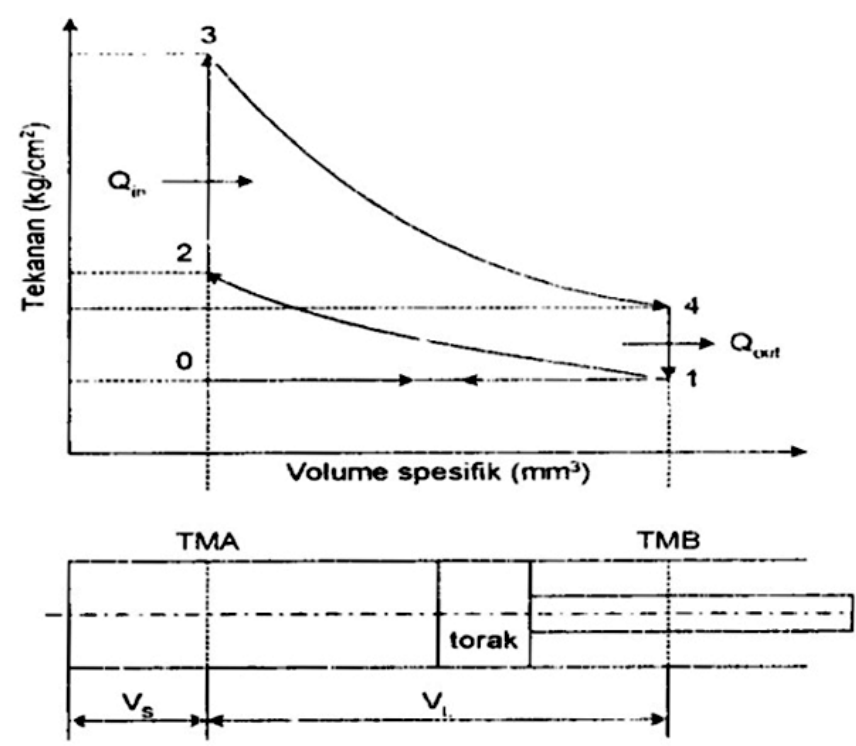

Gambar 3. Diagram P-V siklus otto

Proses siklus otto sebagai berikut :

\section{Proses 0 - 1}

Merupakan langkah hisap bahan bakar dimana piston mulai bergerak dari TDC (Top Death Centre) menuju ke BDC (Bottom Death Centre) dengan posisi katup hisap terbuka dan katup buang tertutup. Akibat dari langkah piston turun ini maka campuran udara bahan bakar akan terhisap, prosesnya terjadi secara isotermis.

\section{Proses 1 - 2}

Merupakan langkah kompresi dimana piston bergerak ke atas lagi menuju TDC setelah melakukan langkah hisap dengan posisi katup hisap dan katup buang tertutup. Langkah ini akan menaikkan tekanan pada ruang bakar yang terisi campuran udara dan bahan bakar menjadi naik, prosesnya terjadi secara adiabatik.

Proses 2 - 3

Merupakan proses pembakaran bahan bakar dimana proses ini terjadi sesaat sebelum akhir dari proses kompresi. Campuran bahan bakar dengan udara yang telah terkompresi mulai terbakar akibat percikan api oleh busi. Akibat proses pembakaran ini maka tekanan dan temperatur di ruang bakar menjadi naik tinggi, prosesnya terjadi secara isovolume/isokhorik.

\section{Proses 3 - 4}

Merupakan langkah kerja dimana piston akan bergerak menuju titik mati bawah akibat dari tekanan yang ditimbulkan proses pembakaran. Pada langkah ini posisi katup hisap dan katup buang masih dalam kondisi tertutup. Selama proses ekspansi ini tekanan dan temperatur mulai turun, prosesnya terjadi secara adiabatik.

\section{Proses 4 - 0}


Merupakan langkah buang dimana pada akhir langkah kerja piston, katup buang terbuka dan katup hisap tertutup dan piston bergerak menuju ke TDC membuang gas pembakaran keluar dari silinder, prosesnya terjadi secara isovolume/ isokhorik.

\section{Langkah Pembakaran Motor Bakar Bensin}

Dalam sebuah mesin terjadi beberapa tingkatan pembakaran yang digambarkan dalam sebuah grafik dengan hubungan antara tekanan dan perjalanan engkol. Grafik dapat dilihat pada Gambar 4.

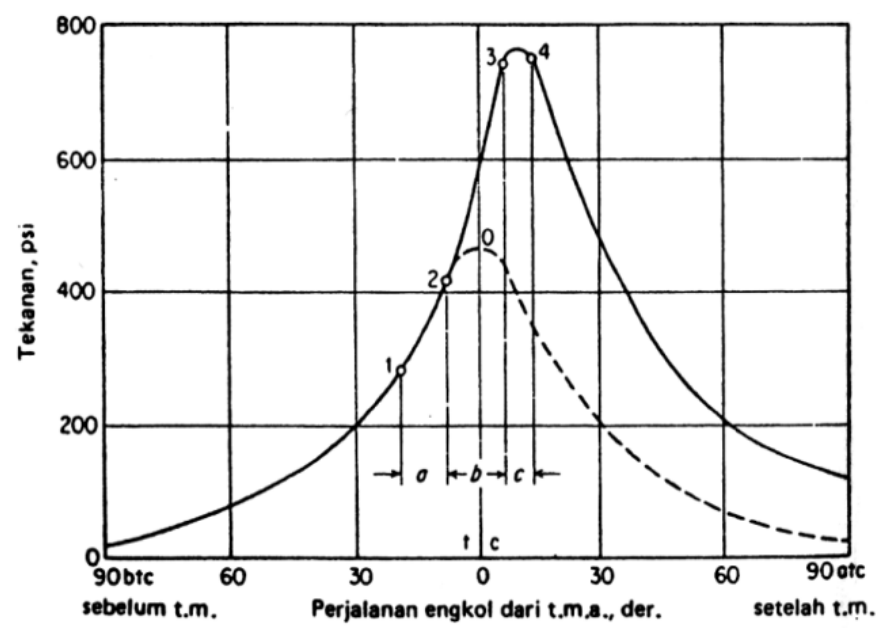

Gambar 4. Langkah pembakaran dalam sebuah mesin

Proses atau tingkatan pembakaran dalam sebuah mesin terbagi menjadi beberapa periode. Periode pertama dimulai dari titik 1-2 (sudut engkol a) yaitu mulai bergeraknya piston dari TMB menuju TMA (awal langkah kompresi), dan pada titik 1 mulai dipercikan bunga api oleh busi, tekanan pun naik seiring dengan mulai bergeraknya piston dari TMB menuju TMA pada langkah kompresi.

Periode kedua dimulai dari titik 2-3 (sudut engkol b) yaitu dimana campuran udara dan bahan bakar yang terkompresi di dalam silinder, setelah campuran udara-bahan bakar dibakar oleh bunga api, maka diperlukan waktu tertentu bagi api untuk merambat di dalam ruangan bakar. Oleh sebab itu akan terjadi sedikit keterlambatan antara awal pembakaran dengan pencapaian tekanan pembakaran maksimum, dan mengakibatkan kenaikan tekanan mendadak sampai pada titik 3 tercapai yang membentuk tingkat kedua pembakaran tertunda (Delay Periode).

Periode ketiga dimulai dari titik 3-4. Periode inilah yang disebut dengan periode terkendali atau disebut juga pembakaran sedikit demi sedikit yang akan berakhir pada titik 4 . Selama tingkat ini tekanan dapat naik, konstan ataupun turun. Periode ini sesuai dengan pejalanan engkol sudut c, dimana sudut c tergantung pada beban yang dibawa beban mesin, semakin besar bebannya semakin besar c. dan sisa pembakaran yang belum terbakar, akan terbakar dengan sendirinya pada saat langkah expansi dari TMA menuju TMB.

\section{Air Vent Tube Turbulence (AVTT)}

AVTT merupakan suatu alat yang berbentuk tabung yang berfungsi meningkatkan kualitas asupan udara kedalam silinder motor bakar, dengan mengubah aliran laminar menjadi aliran turbulen sehingga pembakaran menjadi lebih ideal mendekati sempurna.

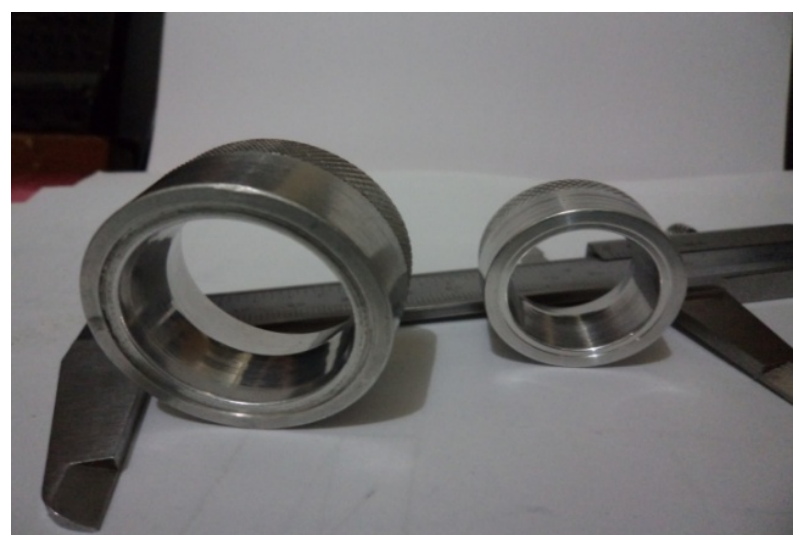

Gambar 5. Air Vent Tube Turbulence(AVTT)

AVTT berguna untuk :

1. Menghemat Pemakaian Bahan Bakar Minyak (BBM)

2. Mengurangi Getaran Mesin (Reduce Engine Vibration).

3. Menambah Akselerasi Kendaraan .

4. Effisiensi Dalam Perawatan Kendaraan.

5. Mengurangi Emisi gas Buang.

\section{Penerapan Hukum Bernoulli pada Efek Venturi}

Persamaan Bernoulli juga bisa diterapkan pada kasus khusus lain yakni ketika fluida mengalir dalam bagian pipa yang ketinggiannya hampir sama (perbedaan ketinggian kecil).

Pada Gambar 6 di bawah tampak bahwa ketinggian pipa, baik bagian pipa yang penampangnya besar maupun bagian pipa yang penampangnya kecil, hampir sama sehingga diangap ketinggian alias h sama. 


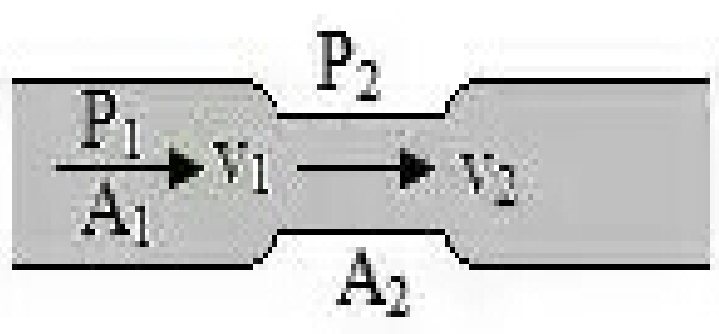

Gambar 6. Tabung Venturi

Jika diterapkan pada kasus ini, maka persamaan Bernoulli berubah menjadi :

$\mathrm{P}_{1}+1 / 2 \rho \mathrm{V}_{1}^{2}+\rho g \mathrm{gh}_{1}=\mathrm{P}_{2}+1 / 2 \rho \mathrm{V}_{2}^{2}+\rho g \mathrm{gh}_{2}$

$\mathrm{P}_{1}+1 / 2 \rho \mathrm{V}_{1}^{2}=\mathrm{P}_{2}+1 / 2 \rho \mathrm{V}_{2}^{2}$

Dimana :

$\mathrm{P}_{1}=$ tekanan pada ujung 1 , (Patm)

$\mathrm{P}_{2}=$ tekanan pada ujung 2, (Patm)

$\mathrm{V}_{1}=$ kecepatan fluida pada ujung $1,(\mathrm{~m} / \mathrm{s})$

$\mathrm{V}_{2}=$ kecepatan fluida pada ujung $2,(\mathrm{~m} / \mathrm{s})$

$\mathrm{h}_{1}=$ tinggi ujung $1,(\mathrm{~m})$

$\mathrm{h}_{2}=$ tinggi ujung $2,(\mathrm{~m})$

Ketika fluida melewati bagian pipa yang penampangnya kecil $\left(\mathrm{A}_{2}\right)$, maka laju fluida bertambah Menurut prinsip Bernoulli, jika kelajuan fluida bertambah, maka tekanan fluida tersebut menjadi kecil. Jadi tekanan fluida di bagian pipa yang sempit lebih kecil tetapi laju aliran fluida lebih besar, demikian pula sebaliknya, jika laju aliran fluida rendah maka tekanan fluida menjadi besar.

\section{Persamaan Kontinuitas}

Persamaan kontinuitas adalah persamaan yang menghubungkan kecepatan fluida dalam dari satu tempat ke tempat lain. Sebelum menurunkan hubungan,kita harus memahami beberapa istilah dalam aliran fluida. Garis aliran (stream line) diartikan sebagai jalur aliran fluida ideal (aliran lunak). Garis singgung di suatu titik pada garis memberikan kita arah kecepatan aliran fluida. Garis alir tidak berpotongan satu sama lain.

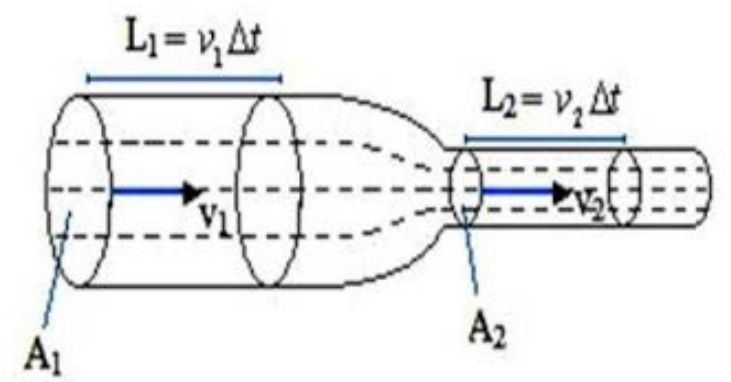

Gambar 7. Aliran fluida dalam pipa

Dimana :

$$
\begin{aligned}
m 1 & =\mathrm{m} 2 \\
\rho_{1} A_{1} V_{1} & =\rho_{2} A_{2} V_{2}
\end{aligned}
$$

$m=$ Laju aliran massa $(\mathrm{kg} / \mathrm{s})$ $\rho=$ Destinitas fluida $\left(\mathrm{kg} / \mathrm{m}^{3}\right)$

$A=$ Luas penampang $\left(\mathrm{m}^{2}\right)$

$V=$ Kecepatan aliran fluida $(\mathrm{m} / \mathrm{s})$

Dari persamaan kontinuitas, perkalian antara luas penampang dan kecepatan fluida pada setiap titik sepanjang tabung aliran adalah konstan. Persamaan di atas menunjukkan bahwa kecepatan fluida berkurang ketika melalui pipa lebar dan bertambah ketika melewati pipa sempit. Tripler.P.A,1998. Fisika untuk Sains Dan Teknik Jilid 1. Jakarta : Erlangga.

Karena $\mathrm{Q}=\mathrm{A} . \mathrm{V}$, maka persamaan kontinuitas dapat bebentuk

$m=\rho_{1} Q_{1}=Q_{2} A_{2}$

Dimana :

$m=$ Laju aliran massa $(\mathrm{kg} / \mathrm{s})$

$\rho=$ Destinitas fluida $\left(\mathrm{kg} / \mathrm{m}^{3}\right)$

$Q=$ Laju aliran volumetric atau Debit aliran $\left(\mathrm{m}^{3} / \mathrm{s}\right)$

Pada pengujian unjuk kerja mesin sepeda motor menggunakan jenis Chassis dynamometer, Chassis dynamometer yang digunakan adalah DynoJet 250i. Dalam unjuk kerja mesin terdapat beberapa parameter utama yang perlu diperhatikan, parameter tersebut merupakan pengaruh dari beberapa kondisi, parameter unjuk kerja meliputi :

1. Torsi (Torque) N.m,

2. Daya (Power) Hp,

3. Air Fuel Ratio (AFR) A/F.

\section{Torsi}

Definisi dari torsi atau momen inersia (rotational force) adalah perkalian antara gaya tangensial dengan jarak lengan berputar. Torsi maksimum biasanya digunakan saat kendaraan mau bergerak dan sedang membawa beban berat, biasa disebut akselarasi/tarikan awal. Analoginya, waktu kita mendorong motor pada saat keadaan diam, sesaat sebelum bergerak akan terasa berat sekali, maka kaki butuh menjejak kuat dan mendorong sekuatnya agar motor bergerak, saat motor sudah melaju/ bergerak maka hanya perlu sedikit torsi, tapi diperlukan lebih banyak daya untuk mendapatkan dan menjaga kecepatan yang tinggi.

Untuk mendefinisikan torsi pada dynamometer adalah dengan persamaan berikut

$$
T=F x l \quad(\text { N.m) }
$$

Dimana :

$\mathrm{T}=$ torsi $(\mathrm{N} . \mathrm{m})$

$\mathrm{F}=$ gaya/force $(\mathrm{N})$

$\mathrm{l}$ = anjang lengan dynamometer $(\mathrm{m})$

Daya 
Daya didefinisikan sebagai laju aliran kerja dan sama dengan perkalian antara gaya linear dengan torsi. Definisi ilmiah dari horse power adalah jumlah energy yang dibutuhkan untuk mengangkat benda seberat 550 lbs setinggi 1 feet dalam waktu 1 detik.

Dalam pengujian unjuk kerja mesin dengan menggunakan chassis dynamometer, untuk pengukuran daya, yang diukur adalah torsi yang dihasilkan oleh roda, yang kemudian menjadi acuan dalam perhitungan daya, selanjutnya untuk mengetahui putaran mesin (rpm) menggunakan tachometer yang sudah ada didalam dynamometer tersebut dengan cara mengkalibrasi antara perputaran roda/ban dengan perputaran roller, selain itu dapat juga menggunakan tachometer manual. Menurut buku Arend, BPM, Barenschot, H. Motor Bensin, Penerbit Erlangga, Jakarta, 1994, hubungan rumus daya dengan torsi adalah dengan fungsi persamaan :

$$
\mathrm{P}=\frac{2 \times \pi \times n \times T}{60 \times 1000}(k W)
$$

Dimana :

$\mathrm{P}=$ Daya Output/daya poros berguna $(\mathrm{kW})$

$\mathrm{n}=$ Putaran $(\mathrm{rpm})$

$\mathrm{T}=$ Torsi / Momen putar/puntir (N.m)

$60=1$ menit

1000 = watt - kilowatt.

\section{Air Fuel Ratio (AFR)}

Pengujian dilakukan dengan mengukur laju aliran udara dan bahan bakar, perbandingan tersebut bertujuan mengetahui pengaturan dalam kondisi operasi motor bakar. Bila kita perhatikan perbandingan ini tidak terlepas dari kecepatan putaran mesin, tingkat $\mathrm{A} / \mathrm{F}$ dimulai dari $9: 1$ sampai $20: 1$. Semakin kecil angka $A F R$ maka akan semakin besar pemakaian bahan bakar dan sebaliknya.

Persamaan air fuel ratio ialah :

Dimana :

$$
A F R=\frac{m_{a}}{m_{f}}
$$

$m_{a}=$ Laju aliran udara $(\mathrm{kg} / \mathrm{s})$

$m_{f}=$ Laju aliran bahan bakar $(\mathrm{kg} / \mathrm{s})$

\section{Konsumsi Bahan Bakar / Fuel Comsumption (FC)}

Karakteristik unjuk kerja suatu motor bakar dinyatakan juga dalam beberapa parameter diantaranya konsumsi bahan bakar dan konsumsi bahan bakar spesifik.
Konsumsi Bahan Bakar / Fuel Consumption (FC)

$$
F_{c}=\frac{V f}{t} \times \rho f \times \frac{3600}{1000}
$$

Keterangan :

$F_{c}=$ konsumsi bahan bakar $(\mathrm{Kg} / \mathrm{jam})$

$V f=$ konsumsi bahan bakar selama t detik (ml)

$P f=$ massa jenis bahan bakar $(\mathrm{kg} / \mathrm{ltr})$

$\mathrm{t}=$ interval waktu pengukuran konsumsi bahan bakar (detik)

$3600=$ jam ke detik

$1000=$ liter ke ml

\section{Volume Langkah (VL)}

Besarnya ruang yang di tempuh oleh piston selama melakukan langkah kerja.

$$
\mathrm{V}_{\mathrm{L}}=\frac{\pi \times D^{2} \times L}{4}
$$

Dimana :

$\mathrm{V}_{\mathrm{L}}=$ Volume Langkah $\left(\mathrm{cm}^{3}\right)$

$\mathrm{D}=$ Diameter silinder $(\mathrm{cm})$

$\mathrm{L}=$ Panjang langkah Piston $(\mathrm{cm})$

\section{Kapasitas Aliran Udara (Q)}

Untuk mengetahui kapasitas aliran udara yang masuk kedalam silinder mesin.

$\mathrm{Q}=\frac{\mathrm{VL} \times \mathrm{Z} \times \mathrm{n} \times 1 / 2}{60 \mathrm{~s}}$

Dimana :

$\mathrm{Q}=$ Debit aliran atau kapasitas aliran $\left(\mathrm{m}^{3} / \mathrm{s}\right)$

$\mathrm{D}=$ Diameter silinder $(\mathrm{m})$

$\mathrm{L}=$ Panjang langkah piston $(\mathrm{m})$

$\mathrm{Z}=$ Jumlah silinder

$\mathrm{n}=$ Putaran mesin (rpm)

$1 / 2=$ Konstanta untuk motor 4 langkah

$1=$ Konstanta untuk motor 2 langkah

\section{Metode Penelitian}

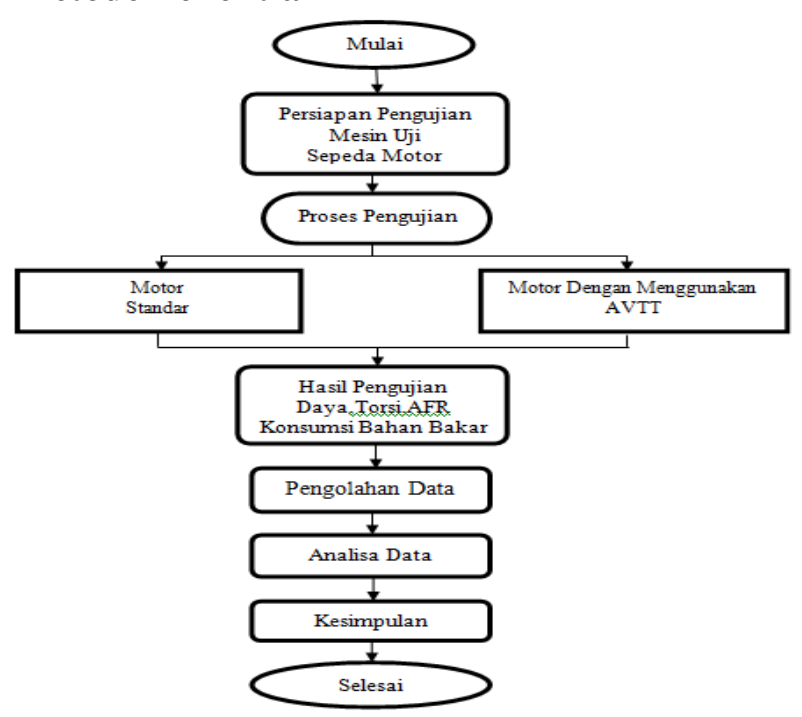

Gambar 8. Diagaram alir penelitian 


\section{Prosedur Persiapan Pengujian Unjuk Kerja Mesin}

Kegiatan persiapan sebelum melakukan pengujian dimaksudkan untuk memperoleh data terukur yang lebih akurat dan presisi. Persiapanpersiapan tersebut mencakup beberapa pemeriksaan diantaranya :

1. Menempatkan sepeda motor di atas chasis dyno test, kemudian mengikatnya dengan strap yang kuat agar posisi ban belakang dari sepeda motor menekan sempurna dan tepat di atas bantalan roller agar torsi dan daya terbaca dengan baik. Posisi sepeda motor yang terikat dengan strap di atas roller.

2. Melakukan pemeriksaan kondisi motor secara umum seperti pemeriksaan bahan bakar, karburator, dan pemeriksaan saluran gas buang/knalpot.

3. Memasang alat Air fuel Ratio (AFR) sensor dengan memasukkan kabel probe pada saluran gas buang/ knlapot (exhaust duct) untuk mendeteksi perbandingan udara dan bahan bakar (Air Fuel Ratio / AFR). Saat melakukan pengujian hasil $A F R$ akan terbaca di monitor.

4. Pengujian dilakukan dimulai dari putaran mesin idle (1500 rpm) - rpm tertinggi motor, guna mengetahui torsi (N.m), dan daya (HP) serta perbandingan udara-bahan bakar (AFR), untuk mendapatkan data hasil pengujian yang sebenarnya.

\section{Prosedur Pengambilan Data Pengujian Unjuk Kerja Mesin}

Seluruh pengambilan data dilakukan di atas mesin dyno test dimana terlebih dahulu harus memposisikan sepeda motor di atas chasis dyno dengan tepat pemasangannya di atas roller. Setelah sepeda motor dan semua alat ukur terpasang dengan baik maka dilanjutkan dengan pengujian sebagai berikut:

1. Menghidupkan mesin sepeda motor dan melakukan pemanasan mesin motor pada kondisi idle untuk mencapai kondisi operasional dari mesin sekitar +/- 5 menit, memasukan data ukuran roda beserta ukuran ban yang digunakan.

2. Menghidupkan blower untuk pendinginan mesin agar saat pengujian berlangsung tidak terjadi over heat pada mesin motor, kemudian menghidupkan exhaust fan untuk menghisap gas buang yang ada di dalam ruangan.

3. Menaikan bukaan gas dari 3500 rpm sampai dengan bukaaan gas penuh (full throttle) atau pada putaran mesin 8500 rpm. Pengujian pertama dimulai dengan penggunaan mesin standar.

4. Selanjutnya setelah pengujian dengan penggunaan mesin standar selesai, dilanjutkan pengujian dengan pemasangan Air Vent Tube Turbulent ( AVTT ), kemudian menurunkan gas kembali pada posisi idle.

\section{Prosedur Pengujian Konsumsi Bahan Bakar}

Sebelum mengadakan pengujian konsumsi bahan bakar, pastikan alat yang akan di gunakan terpasang dengan baik pada posisinya. Langkah - langkah pengujian konsumsi bahan bakar sebagai berikut :

1. Menghubungkan buret dengan karburator mengunakan selang, kemudian letakan buret pada posisi lebih tinggi dari karburator.

2. Mengisi bensin pada buret sampai sedikit melebihi batas takaran $100 \mathrm{ml}$.

3. Menghidupkan mesin dan memanaskan sepeda motor pada kondisi idle untuk mencapai kondisi operasional mesin sekitar \pm 5 menit.

4. Mengukur laju aliran bahan bakar dengan mengatur gas pada kondisi idle 1500 rpm pada display tachometer,

5. Kemudian mulai melihat posisi besin pada buret, apabila besin tepat pada ukuran 100 $\mathrm{ml}$. Mulailah menghitung dengan stopwatch dan mencatat waktu yang di butuhkan dari posisi bensin $100 \mathrm{ml}$ sampai $90 \mathrm{ml}$ dan seterusnya sampai besin dalam buret habis.

6. Mengisi kembali bensin pada buret kemudian mulai kembali seperti langkah diatas dengan mengatur posisi gas pada kondisi 2000 rpm, 3000 rpm, 4000 rpm dan $5000 \mathrm{rpm}$.

7. Setelah pengujian dengan mesin standart selesai, maka selanjutnya pengujian dengan memasang Air Vent Tube Turbulent (AVTT). Kemudian dimulai pengujian dengan menurunkan gas kembali ke posisi idle 1500 rpm, lakukan sesuai langkah 45 dan 6 . 


\section{ANALISIS DATA \\ TORSI}

Torsi Mesin Varian 1

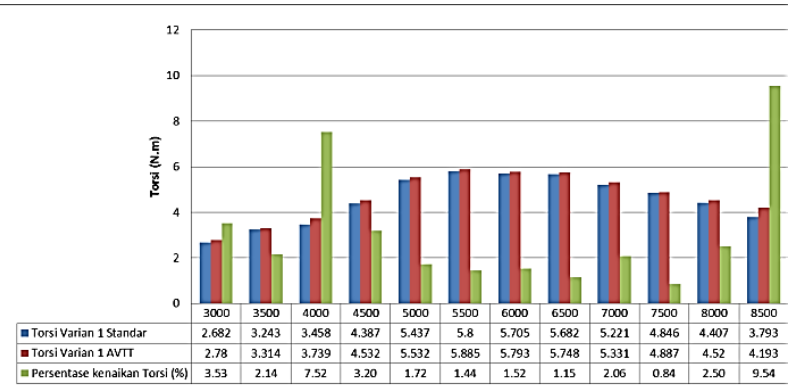

Gambar 9. Grafik torsi mesin varian 1

Grafik hasil pengujian torsi mesin motor matik varian 1 menunjukan adanya kenaikan torsi motor di setiap putaran setelah menggunakan AVTT. Torsi maksimum berada pada putaran mesin 5500 rpm yaitu 5,800 N.m setelah menggunakan AVTT naik menjadi 5,885 N.m. jadi besarnya persentase kenaikan torsi $1,44 \%$.

Torsi Mesin Varian 2

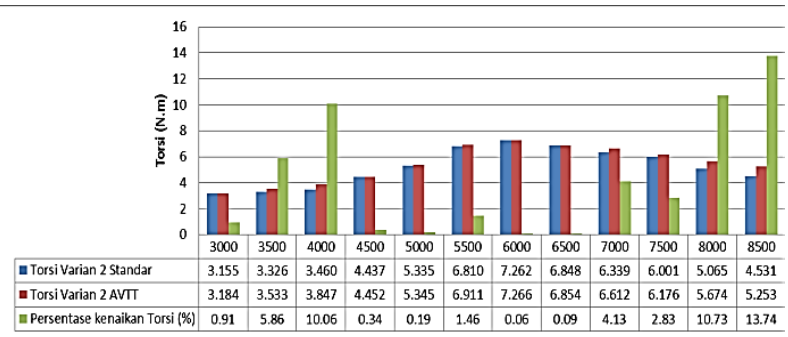

Gambar 10. Grafik torsi mesin varian 2

Gambar grafik torsi mesin motor varian 2 menunjukkan adanya kenaikan torsi mesin setelah menggunakan AVTT. Torsi maksimum mesin motor varian 2 berada pada putaran mesin 6000 rpm yaitu 7,262 N.m, setelah menggunakan AVTT naik menjadi 7,266 N.m. Jadi besarnya kenaikan torsi $0,06 \%$.

\section{DAYA}

Daya Mesin Varian 1

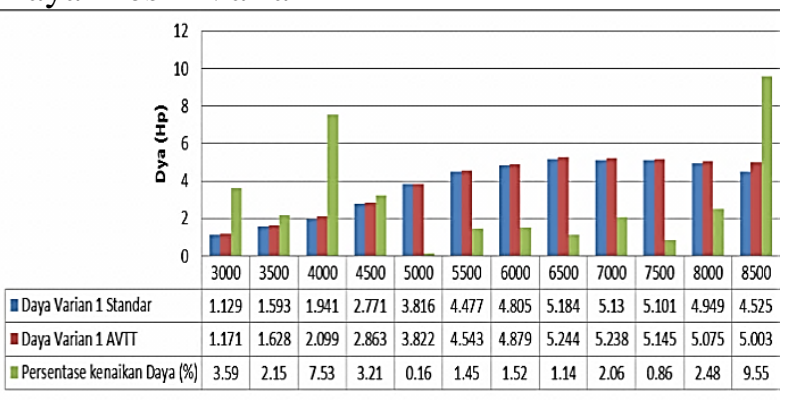

Gambar 11. Grafik daya mesin varian 1

Gambar grafik daya mesin motor varian 1 menunjukan adanya kenaikan daya mesin setelah menggunakan AVTT. Daya maksimum mesin motor varian 1 berada pada putaran mesin 6500 rpm yaitu 5,184 Hp, setelah menggunakan AVTT naik menjadi 5,244 Hp. besarnya kenaikan daya $1,14 \%$.

\section{Daya Mesin Varian 2}

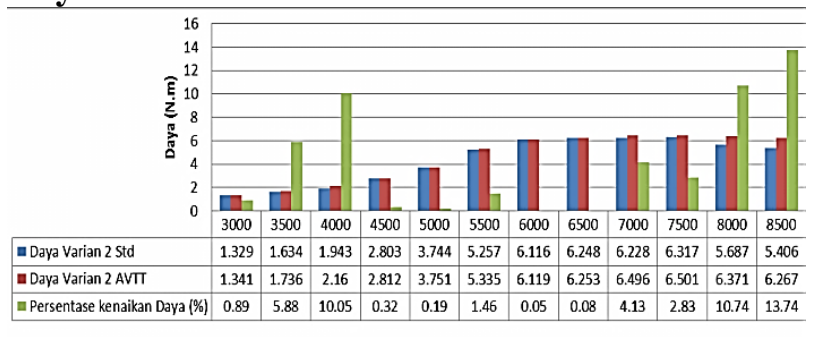

Gambar 12. Grafik daya mesin varian 2

Gambar grafik daya mesin motor varian 2 menunjukan adanya kenaikan daya mesin setelah menggunakan AVTT. Daya maksimum mesin motor varian 2 berada pada putaran mesin 7500 rpm yaitu 6,317 Hp, setelah menggunakan AVTT naik menjadi 6,501 Hp. jadi besarnya kenaikan daya $2,83 \%$.

\section{PERBANDINGAN AIR FUEL RATIO (AFR)}

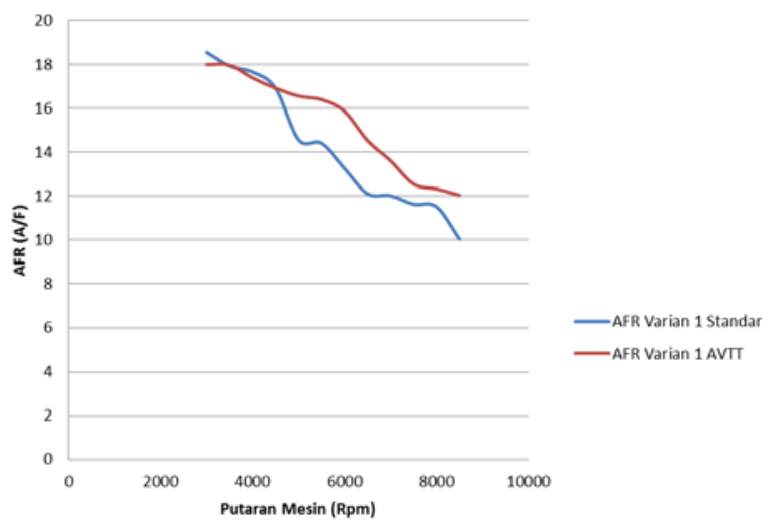

Gambar 13. Grafik Air Fuel Ratio

Perbandingan $\boldsymbol{A F R}$ pada pengujian dynamometer pada kedua varian mesin motor matik ,perbandingan ini tidak terlepas dari kecepatan putaran mesin. Tingkat A/F dimulai dari $18: 1$ sampai $10: 1$. Semakin kecil angka AFR maka akan semakin besar pemakaian bahan bakar dan Semakin besar angka AFR maka akan semakin kecil atau sedikit dalam pemakaian bahan bakar. 
KONSUMSI BAHAN BAKAR

Konsumsi Bahan Bakar Mesin Varian 1

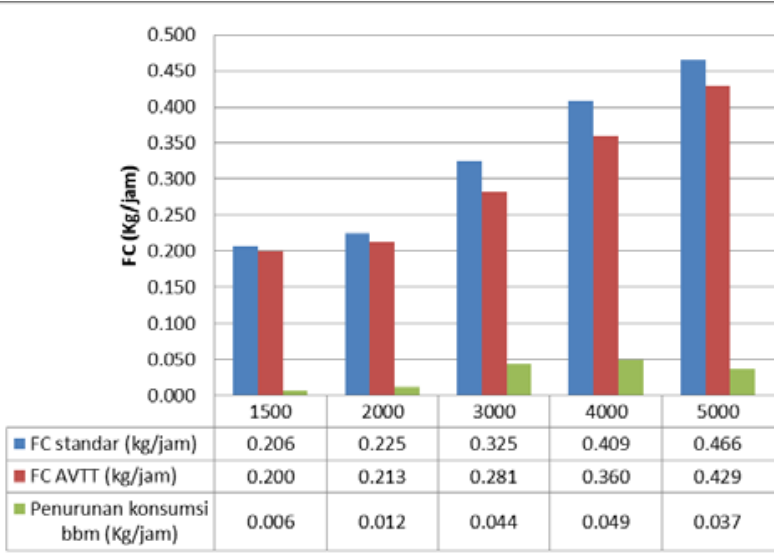

Gambar 14.Grafik konsumsi bahan bakar mesin varian 1

Pada grafik di atas menunjukan adanya penurunan konsumsi bahan bakar mesin motor varian 1 setelah menggunakan AVTT. Penurunan konsumsi bahan bakar di setiap putaran mesin mulai dari 0,006-0,037 kg/jam.

Konsumsi Bahan Bakar Mesin Varian 2

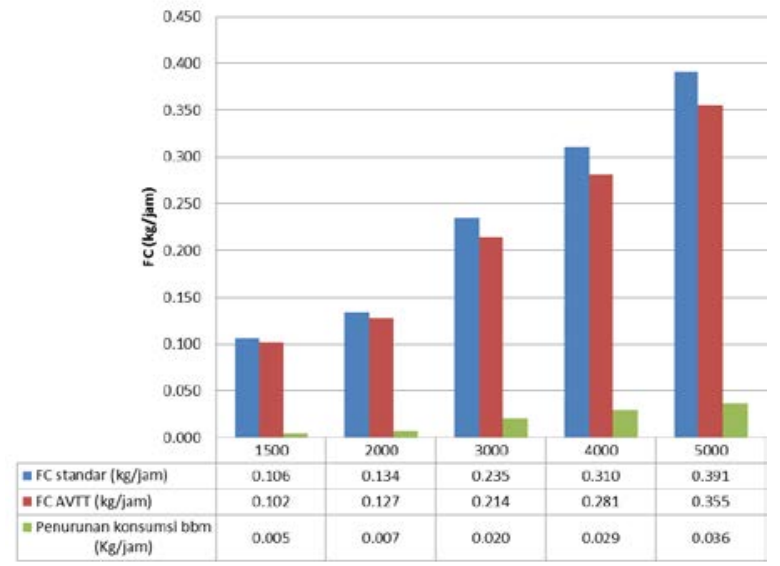

Gambar 15. Grafik konsumsi bahan bakar mesin varian 2

Pada grafik di atas menunjukan adanya penurunan konsumsi bahan bakar mesin motor varian 2 setelah menggunakan AVTT. Penurunan konsumsi bahan bakar di setiap putaran mesin mulai dari 0,005-0,036 kg/jam.

\section{PERBANDINGAN KECEPATAN ALIRAN UDARA}

Secara teori kita dapat mengetahui perbandingan kecepatan aliran udara dan jenis aliran yang masuk kedalam silinder ruang bakar mesin motor.
Kecepatan Aliran Udara Mesin Varian 1

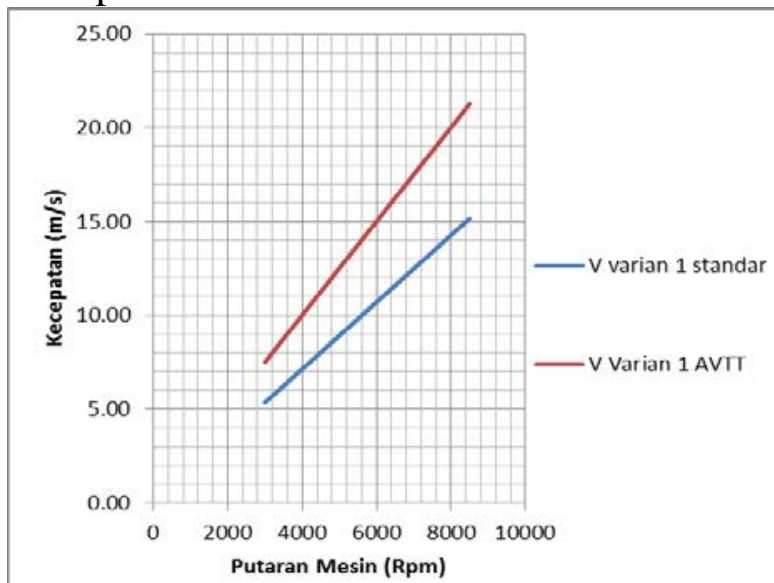

Gambar 16. Grafik kecepatan aliran udara mesin varian 1

Dari hasil perhitungan pada mesin motor varian 1 di ketahui setelah menggunakan AVTT kecepatan aliran udaranya bertambah. Pada gambar grafik diatas menunjukan kecepatan aliran udara sebelum 5,35 - 15,17 $\mathrm{m} / \mathrm{s}$ dan sesudah menggunakan AVTT 7,51 - 21,28 m/s.

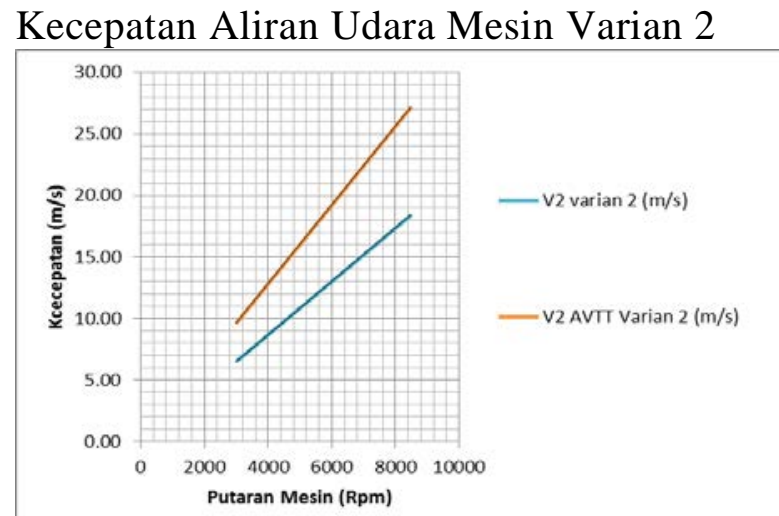

Gambar 17. Grafik kecepatan aliran udara mesin varian 2

Grafik hasil perhitungan kecepatan aliran udara pada mesin motor varian 2. pada grafik menunjukan bahwa kecepatan aliran udara sebelum menggunakan AVTT 6,50 - 18,41 m/s. setelah menggunakan AVTT kecepatan aliran udaranya bertambah menjadi 9,12 -25,83 m/s.

\section{JENIS ALIRAN}

Untuk mengetahui jenis aliran udara yang masuk kedalam silinder ruang bakar, Apabila angka RE <2000 laminar, RE $>4000$ turbulen dan apabila RE berada di antara 2000 sampai 4000 berarti aliran transisi.

Jenis Aliran Mesin Varian 1 


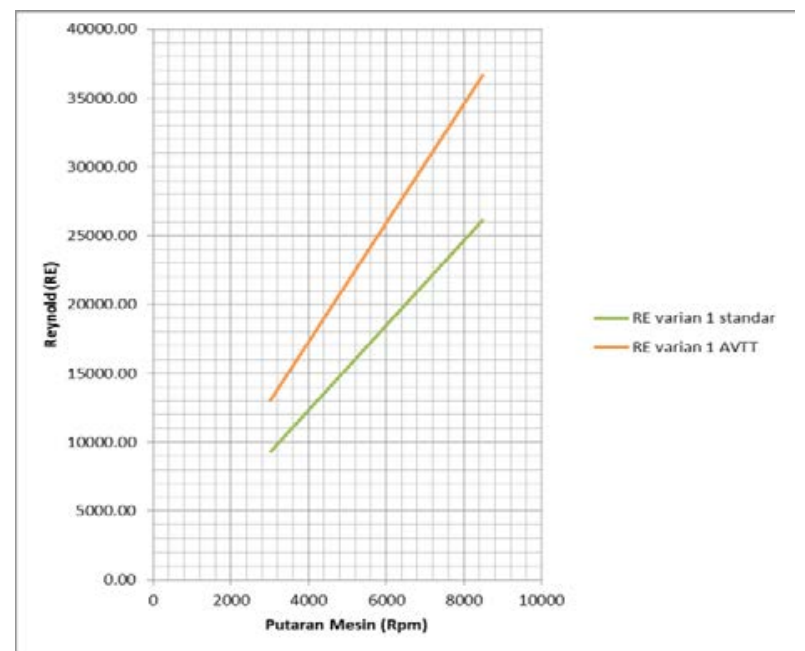

Gambar 18. Jenis aliran pada mesin varian 1

Pada grafik diatas menunjukan jenis aliran mesin motor varian 1 adalah turbulen karena RE $>4000$.

Jenis Aliran Mesin Varian 2

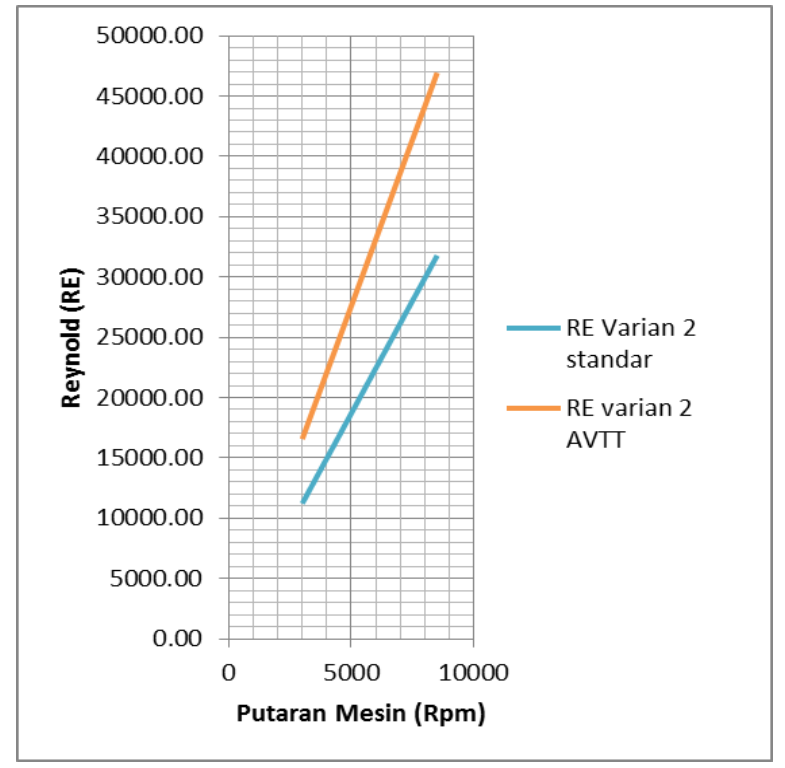

Gambar 19. Jenis Aliran MesinVarian 2

Pada grafik diatas menunjukan jenis aliran mesin motor varian 2 juga turbulen karena RE > 4000 .

\section{KESIMPULAN}

Dari hasil pengujian pengaruh penggunaan Air Vent Tube Turbulen (AVTT) terhadap kinerja mesin motor matik 4 langkah, maka dapat di simpukan beberapa hal sebagai berikut :

1. Torsi pada mesin motor varian 1 naik 0,84 9,54 persen setelah menggunakan AVTT, sedangkan pada mesin motor varian 2 torsinya naik 0,06 - 13,74 persen setelah menggunakan AVTT.

2. Daya pada mesin motor varian 1 naik 0,16 9,55 persen setelah menggunakan AVTT, sedangkan pada mesin motor varian 2 dayanya naik 0,08 - 13,74 persen setelah menggunakan AVTT.

3. Untuk Air Fuel Ratio (AFR) pada dua jenis varian motor matik perbandingannya tidak terlepas dari kecepatan putaran mesin, tingkat $\mathrm{A} / \mathrm{F}$ dimulai dari $18: 1$ sampai 10 : 1. Semakin kecil angka $A F R$ maka akan semakin besar pemakaian bahan bakar dan Semakin besar angka AFR maka akan semakin kecil atau sedikit dalam pemakaian bahan bakar.

4. Konsumsi bahan bakar pada mesin motor varian 1 mengalami penurunan setelah menggunakan AVTT sebesar 2 - 7 \% untuk setiap kenaikan putaran mesinnya. Sedangkan pada mesin motor varian 2 juga mengalami penurunan konsumsi bahan bakarnya setelah menggunakan AVTT sebesar 3 - $9 \%$.

5. Terjadinya peningkatan kecepatan aliran udara yang masuk ke ruang silinder motor setelah mesin motor menggunakan AVTT.

\section{DAFTAR PUSTAKA}

Arends BPM, B. H. (1980). Motor Bensin. Erlangga: Jakarta.

Cengel \& Boles, Michael A : Thermodynamic An engineering Aproach,McGraw- Hill International, 1994.

Arismunandar, Wiranto. Penggerak Mula Motor Bakar Torak, Edisi 4, Penerbit ITB, Bandung, 1988.

Wiranto, Arismunandar. Penggerak Mula Motor Bakar Torak, Edisi 5, Penerbit ITB, Bandung, 2005.

VL. Maleev, ME., Dr. A.M. ,Internal Combustion Engine Theory and Design , McGraw-Hill International Book Company, 1945

Boogs, Sam., Principles of sedimentology and stratigraphy and, 1995 Prentice Hall Frits, and Moor

JurnalIlmiah :( JosephDiPardo. "Outlook for Biomass Ethanol Production and Demand" (PDF). United States Department of Energy. )

( Windholz, Martha (1976). The Merck index: an encyclopedia of chemicals and drugs (edisi ke-9th). Rahway, N.J., U.S.A: Merck. ISBNO-911910-26-3)

Frederick D. Rossini (1937). "Heats of Formation of Simple Organic 
Molecules".Ind. Eng. Chem.29 (12): 1424 1430 )

Pengaruh Rasio Kompresi terhadap Unjuk Kerja Mesin Empat Langkah Menggunakan Arak Bali sebagai Bahan Bakar, I Dewa Made Krishna Muku \& I Gusti Ketut Sukadana Jurusan Teknik Mesin, Universitas Udayana, Kampus Bukit Jimbaran Badung $2009 \quad e$-mail: e-mail: krisna.muku@me.unud.ac.id

Popo. (2006). Cara Kerja Untuk Menggunakan Alat Uji Dynamometer Chasis, http://viozaax.wordpress.com/2006/07/19/ mengenal-dynamometer/,dipetik 26/05/2012.

Fahmi Alfa Muslimu, Analisa Aliran Udara Pada Elbow Proto $X-1$ Menggunakan CFD.Teknik Mesin UI, 2012

http://www.yamaha-motor.co.id

http://www.land-and-

sea.com/ selector/motorcycle/chassis/13/I nertia/057-650-1K_specifications.htm)

www.dynojet.com/250i.

https://taufiqurrokhman.wordpress.com/2014/01/ 03/aliran-fluida-dalam-pipa/

Analisis Pengaruh Penggunaan Bahan Bakar Pertamax Dadn Pertamax Plus Terhadap Performa Sepeda Motor Dengan Menggunakan Dinamometer Chasssis , Umar Farouk Abul Haq dan Tabah Priangkoso, Program Studi Teknik Mesin Fakultas Teknik Universitas Wahid Hasyim Semarang 2 Oktober 2013 